\title{
Least action principle, equilibrium states, iterative adjustment and the stability of alluvial channels
}

\author{
Gerald C. Nanson ${ }^{*}$ and He Qing Huang ${ }^{2}$ \\ School of Earth and Environmental Sciences, University of Wollongong, NSW, Australia \\ ${ }^{2}$ Institute of Geographical Sciences and Natural Resources Research, Chinese Academy of Sciences, Anwai, Beijing, China
}

*Correspondence to: Gerald

Nanson, School of Earth

and Environmental Sciences,

University of Wollongong,

NSW 2522, Australia.

E-mail: gnanson@uow.edu.au

\begin{abstract}
The energy based least action principle (LAP) has proven to be very successful for explaining natural phenomena in both classical and modern physics. This paper briefly reviews its historical development and details how, in three ways, it governs the behaviour and stability of alluvial rivers. First, the LAP embodies the special stationary equilibrium state of motion and so its incorporation with the principle of energy conservation explains why so many optimizing hypotheses have been proposed in fluvial geomorphology. Second, the variational approach underlying the LAP provides a more straightforward and simpler fuzzy-object orientated method for solving river regime problems than do the various complex Newtonian formulations. Third, it is shown that in fluvial systems with surplus energy the surplus can be expended with slope and/or channel geometry adjustments, with the degree of channel geometry adjustment quantified by the dimensionless numbers $F$ for depth dominated adjustment and $\boldsymbol{H}$ for width/depth dominated adjustment. Different planforms are preferred at different energy levels, with $H$ providing a quantitative measure of the flow's efficiency for moving sediment. In rivers with insufficient energy, the interactions of endogenous and exogenous factors are shown to be capable, in certain circumstances, of achieving a stationary equilibrium condition which acts as the attractor state. Importantly, this study describes how iterative changes enable systems to achieve such a stable equilibrium. Copyright (C) 2007 John Wiley \& Sons, Ltd.
\end{abstract}

Keywords: least action; equilibrium states; extremal hypotheses; iterative change; variational principles; river patterns; channel stability
Received 26 July 2006;

Revised 12 June 2007;

Accepted 28 June 2007

\section{Introduction}

Rivers are natural 'machines', consuming energy to do work as they act in concert with other geomorphic agents to erode landscapes and transport the resulting detritus. Indeed, Ferguson (1981) described them as being like a conveyor belt, moving sediment intermittently towards base level. Because they convey highly variable amounts of water and sediment over time and space, they are often elusive in revealing clear patterns of behaviour. However, empirical studies over more than a century have shown that collectively alluvial rivers exhibit surprisingly uniform average characteristics (Leopold and Maddock, 1953). Across the globe they are subject to different climates, biomes, topographies, lithologies and geological structures, so why is it that they do not vary spatially or temporarily more than they do? Channel hydraulics appears to be governed by a relatively simple unifying principle. This study focuses on alluvial rivers with uniform mobile boundaries but later considers alluvial rivers with non-uniform boundaries, where exogenous (externally imposed) factors play a vital role in achieving a stable equilibrium state.

Those variables most immediate to the operation of an alluvial river as a mechanical system are water discharge, channel gradient, sediment load and sediment calibre. The first of these is a largely independent variable and the remaining three are less so. The first two determine the system's operational energy (power) and the second two determine the work it must do. Consequently, rivers are often the product of a balance, and sometimes an imbalance, between work achieved and energy consumed. For this reason a first approximation of a river's form and behaviour can be made from an analysis of its overall operational mechanics. Crucial to this analysis is the recognition that, in 
many cases, not all the energy available to a river is used to do work. In fact, three possibilities exist: (1) a river may have more energy than that required to move its water and sediment load, in which case it has surplus energy and will be unstable; (2) it may have exactly that required, in which case it is stable, and (3) it may have an energy deficit, which will also result in instability, but different to that caused by surplus energy. We argue that most alluvial rivers fall in the middle category and that this is not because there is a remarkable global coincidence between valley gradients and the work that rivers must do. Alluvial rivers can often achieve stability because, within a definable range of conditions, they are self-adjusting systems that can expend any energy that is surplus to their optimally efficient operation, or they can adjust to conserve energy should they be underpowered. In this paper we argue that such changes are not a teleological proposition but that they occur iteratively with the direction of any change based on probability.

The energy that a river has to accomplish work along its path length can be expressed very simply as stream power (Bagnold, 1966):

$$
\Omega=\gamma Q S
$$

where $\Omega$ is the total stream power, $\gamma$ is the specific weight of water, $Q$ is the water discharge and $S$ is the channel slope. In alluvial channels, slope comes in two parts; that dictated by valley gradient, which is determined independently of the contemporary river (i.e. an exogenous variable), and that which the channel can alter by adjusting its path length and is hence dependent on the river's operation (i.e. an endogenous variable). Because $\gamma$ is essentially fixed and $Q$ is largely independent, only slope can be altered, and then only partially so within parameters determined by the gross form of the valley (gradient and width). For this reason, channel slope is a critical albeit only partially variable means of energy self-adjustment in rivers.

The Earth's crust is in many places dynamic and climate has in the recent geological past at times been highly erosional. As a consequence, local tectonism, volcanism, glaciation and palaeo-climates ensure that many of the world's valleys are substantially steeper than is necessary to move today's slowly forming weathering and erosional products to base level. Yet even in cases where there is considerable excess energy, a river does not usually behave as if out of control, like a machine with no governor, for this would lead to severe erosional instability. In such cases a natural system of 'brakes' is applied; the cross-sectional, bedform and planform morphologies of channels rapidly adjust and most surplus energy is expended in frictional losses (heat). As will be discussed later, some of the surplus is also used for other work, such as eroding and reforming channels, bars and floodplains. The resulting equilibrium channels are adjusted to have available only the energy required for moving the water and sediment supplied. This is what Mackin (1948) called a graded stream. Such streams are self regulating systems, with negative feedback or homeostasis maintaining a balanced or equilibrium condition.

Because of limited bank strength, most alluvial rivers have large width/depth ratios (Church, 1992), certainly larger than for the most efficient hydraulic section which, for a channel transporting only water in a rectangular section, would have a value of just two (Chow, 1959). Rivers with excess potential energy (valley gradient) consume some of their surplus energy in the form of frictional losses over wide inefficient cross sections. However, despite this, most still have surplus energy and need to adjust their planform to achieve equilibrium.

There has developed in geomorphology an implicit assumption that rivers must have excess energy and that this is controlled by maximizing friction (Davies and Sutherland, 1980, 1983; Eaton et al., 2004) or minimizing stream power (Chang (1979a, 1979b, 1980a, 1980b, 1985, 1988; Millar and Quick, 1993, 1998; Millar 2005). However, as indicated above, there are cases where, rather than having an excess gradient, a valley slope can be too low for the equilibrium transport of sediment in the usual form of a wide single channel. In such cases cross-sectional adjustments can conserve energy, enhance sediment throughput and prevent such rivers becoming unstable through excessive deposition. Except in deltas and depositional basins, situations where rivers have insufficient energy appear to be uncommon and have therefore been the subject of only limited detailed hydraulic investigation (e.g. Nanson and Huang, 1999; Jansen and Nanson, 2004; Tabata and Hickin, 2003; Abbado et al., 2005).

This paper focuses on our least action interpretation of how rivers adjust towards conditions that minimize change and maximize operational efficiency. We review our earlier work on this topic (Huang and Nanson, 2000, 2002, 2004; Huang et al., 2004a), showing how channel cross-sections and planform adjustments combine to achieve the most efficient equilibrium state. Importantly, we show how iterative changes enable systems to achieve stable equilibrium, but we accept that some rivers remain relatively unstable and, while homeostasis continues to promote a degree of self-adjustment and stability, because of the imposed conditions they nevertheless operate outside the range of a fully graded or stable equilibrium condition. To assist the reader we provide a brief review of the historical development of the least action principle (LAP) and the use of extremal hypotheses in geomorphology, and we explain our use of an often confusing nomenclature associated with equilibrium concepts. 


\section{Equilibrium States}

Equilibrium concepts in geomorphology have resulted in confusion, with Thorn and Welford (1994) completing a comprehensive review of the problems. Indeed, some have essentially recommended the abandonment of any notion of equilibrium in geomorphology (e.g. Phillips, 1992; Richards, 1999), except perhaps as a metaphor (Bracken and Wainwright, 2006). In part, misconceptions have resulted because in statics and dynamics, including fluid dynamics, equilibrium is expressed from the perspective of energy or force balances. In contrast, fluvial geomorphologists, such as Gilbert (1877) and Mackin (1948), are interested in longer-term fluxes and time-averaged mass balances (erosion and deposition), and these have been more readily interpreted visually by stepping even further away from energy balances to evaluate time-averaged changes in landform morphology. Different meanings for the same terms in different disciplines do not greatly matter as long as their use is clearly defined. Here we adopt the equilibrium terms used in statics and dynamics, except for the mass-balance case specified below.

Equilibrium is closely related to the stability of an object (the terms are often used interchangeably), and how the object responds to a small displacement force is important. For an object in neutral equilibrium, the result is no net force on the object (Figure 1(c)). In unstable equilibrium the result is an additional force acting in the same direction as the initial displacement (Figure 1(a)). In 'stable equilibrium' a small displacement produces a negative or restoring force opposite to that of the original displacement (Figure 1(b)), but because this opposite force often overcompensates, the system will tend to oscillate about the mean condition.

In statics and dynamics, if an object is stationary, it is in 'static equilibrium' and if it is moving at a constant velocity then, only relative to an observer moving in the same direction at the same speed, it is static and it can be said in general to be in 'dynamic equilibrium'. More importantly, the latter term also applies in dynamics if the object is moving in a periodic form where its motion is attracted to a special equilibrium state known as stationary equilibrium (Thorn and Welford, 1994). A swinging pendulum embodies a typical form of dynamic equilibrium, where the perpendicular position is the point of stationary equilibrium (Figure 2). The stationary equilibrium state is associated

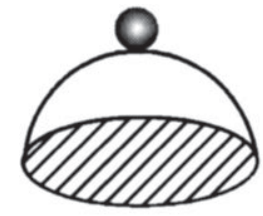

(a)

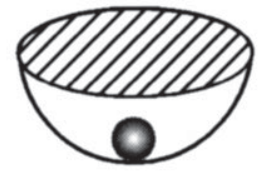

(b)

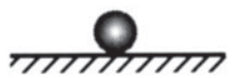

(c)

Figure I. Equilibrium states in a static system: (a) unstable equilibrium; (b) stable equilibrium; (c) neutral equilibrium.

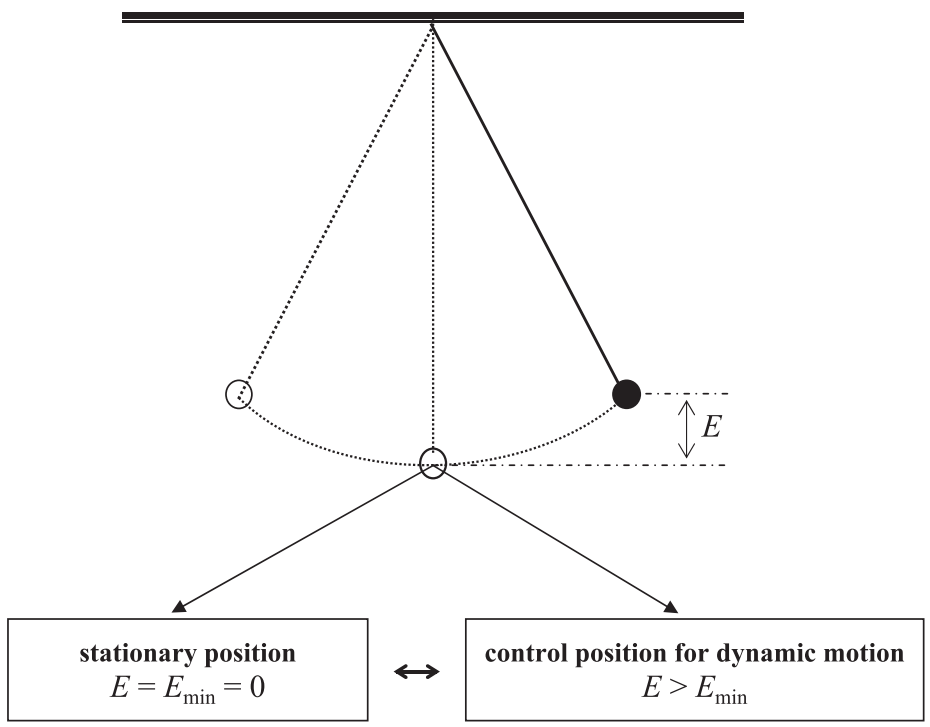

Figure 2. Equilibrium states in the dynamics of pendulum motion. 
with negative feedback or homeostasis, so it can be regarded as characterizing stable equilibrium in a dynamic system. In this context, a meandering river is also in a state of dynamic equilibrium. It oscillates to reduce its gradient (potential energy) and to consume kinetic energy, a straight channel at a lower gradient being its attractor or stableequilibrium state. Clearly, the dynamic equilibrium term defined in dynamics has a very different meaning to that based on mass fluxes and balances adopted for more than a century in geomorphology. To avoid confusion, we use dynamic equilibrium as in dynamics, and for its traditional geomorphic interpretation (a balance between input and output) we adopt the term mass-balance equilibrium of Thorn and Welford (1994).

\section{LAP (least action principle) and the Extremal Hypotheses in Geomorphology}

\section{History of the LAP}

Since Newton's Principia (Philosophiae Naturalis Principia Mathematica) was published in 1687, the concepts of force and momentum have gained wide application in providing quantitative explanations for physical phenomena. In 1746, however, the dominance of the two concepts was challenged by Pierre-Louis Maupertuis with the introduction of the least action principle (LAP). The LAP contains a curious and subtle twist on Newton's laws, for its variational formulation of motion does not use force and momentum but instead the physical quantities of energy and work whose definition does not depend on any coordinate system (vectors). Importantly, the LAP demonstrates that, out of many possible alternatives, nature follows the path that is most 'economical' in terms of work (e.g. Lanczos, 1952; Dugas, 1957; Stauffer and Stanley, 1989; Kroemer, 1994). Since its introduction, the LAP has received strong support from a number of notable physical mathematicians, typically Euler, Lagrange, Hamilton and Jacobi. To many, the LAP provides an effective way of unifying subjects and consolidating theories in various branches of science in terms of the broad similarities between various areas of physics (see, e.g., Lanczos, 1952). During the 18th and 19th centuries it allowed the derivation of the Euler-Lagrange equations relating the velocity, time and space dependency, thereby leading to the formation of the analytical or variational branch of classic mechanics. By the end of the 19th century, the LAP had become an accepted approach not only in classic mechanics but also in electrodynamics and thermodynamics (Dugas, 1957).

During the 20th century more widespread applications of the LAP were developed, and in the 1940s Feynman identified the applicability of the LAP in quantum physics (Brown, 2005). Since then, physicists have found that the LAP also underlies the fundamental gauge theories of particle physics, leading to the establishment of what is termed fundamental physics (Brown and Rigden, 1993). LAP has also been applied widely outside physics. A notable example is the study of Zipf, who, within the context of the LAP, tried to derive the power-law form of his law for understanding the behaviour of humans on the basis of a principle of least effort (Zipf, 1949). With the wide adoption of fractal theory in the 1970s, Zipf's 'law' became ever more popular and has been regarded as one of the essential phenomena of nature. It occurs not only in the distribution of words but also in the occurrence of cities, populations, wars, species, coastlines, floods, earthquakes and many other processes and behaviours (Schroeder, 1991).

In view of the significant move of modern theoretical physics away from classical Newtonian mechanics, the 2004 Nobel Physics Laureate Frank Wilczek (2004) stated that the concept of force is conspicuously absent from the most advanced formulations of the basic laws. It does not appear in Schrödinger's equation, in any reasonable formulation of quantum field theory or in the foundations of general relativity. That science has advanced to its present stage appears to be due to an increasing reliance on variational principles (those based on energy rather than forces) to explain the more complex and profound relationships in nature. This led some observers, even before the emergence of relativity and quantum mechanics, to call for abolition of the concept of force in solving complex dynamic problems (e.g. Russell, 1997).

Since its introduction the LAP has also experienced vociferous opposition from the supporters of pure Newtonian mechanics. They argue that the LAP and its associated variety of variational approaches contain no new physical content in themselves and rarely simplify the practical solution of a given mechanical problem (e.g. Goldstein, 1950). They also argue that the LAP ignores the detailed processes of interactions that initialize and govern the performance of dynamic motions and is thus a teleological concept (e.g. Goldstein, 1950). Indeed, the pioneer of the LAP, PierreLouis Maupertuis, even claimed that the LAP proved the existence of God, perhaps the ultimate teleological proposition! For these reasons, the LAP has been regarded as one of the most controversial principles in the history of science.

A variational approach has been undertaken in fluvial geomorphology and hydraulic engineering in the form of the optimal or extremal hypotheses, to be discussed further below. Opposed to their use, Griffiths (1984) commented that 
they only offer an illusion of progress, and Mosselman (2000, 2004) argued that the LAP and the associated extremal hypotheses are not needed. To such researchers, only the Newtonian formulations are regarded as a truly rational approach, for such formulations are based on the detailed processes of the interactions between the forces of flow acting on a channel boundary and the resisting forces from the boundary. However, major questions relating to how rivers maintain stable channel forms have not been resolvable using Newtonian formulations. Their use for solving river regime problems has been appropriate only for dealing with site-specific issues, such as local bank stability and stable profiles at individual cross-sections. This is because the Newtonian calculations for self-forming channels are extremely complicated (see, e.g., Parker, 1978a, 1978b, 1979; Ikeda, 1981; Ikeda et al., 1988; Pizzuto, 1990; Kovacs and Parker, 1994; Vigilar and Diplas, 1997, 1998) and need to be simplified so as to produce generally applicable theory with which to explain river flow and channel-form interactions (see, e.g., Phillips, 1991; Knighton, 1998; Huang and Nanson, 2002). Newtonian mechanics has certainly enabled approximate and greatly averaged descriptions and models of the forces and motions operating in simple idealized individual channels. However, the complexities associated with the development of erosion-resisting forces in rivers that have abundant but variable riparian vegetation and strong but variable banks have meant that Newtonian mechanics has not been able to explain the remarkably consistency of river form and styles globally.

\section{Extremal hypotheses in geomorphology}

Born from the frustration of interpreting the properties of rivers directly from conventional fluid mechanics, fluvial geomorphology has seen proposals for various extremal or optimizing hypotheses. The first formally proposed and popularly received was that by Leopold and Langbein (1962), who advocated that an alluvial system is analogous to an open thermodynamic system and that the second law of thermodynamics in relation to energy is therefore applicable. From this, Langbein (1964) and Leopold and Langbein (1962) deduced that the extreme condition controlling the adjustment of alluvial channel geometry was minimum variance. Yang (1971) also drew an analogy between thermodynamic and fluvial systems, with elevation (or potential energy) analogous to absolute temperature, and as a result he provided an explanation for drainage network structure and river channel morphology. This led to the suggestion of minimum energy dissipation rate (mEDR) as a general theory in fluvial hydraulics (Yang, 1971, 1972, 1976, 1987; Song and Yang, 1980, 1982; Yang et al., 1981).

However, the approaches by the Leopold and Langbein and Yang research groups were incomplete descriptions of the total system, for they did not recognize that sediment transport has a profound effect on channel form. Taking this into account, Pickup (1976) and Kirkby (1977) proposed the hypothesis of maximum sediment transporting capacity (MSTC), because they saw it as intuitively logical that alluvial channels should be involved in a maximizing process of transporting water and a range of sediment sizes. Although the study by Pickup (1976) focused on the relationship between the optimum shape of natural streams for bedload transport and the return periods of flow discharge, the theoretical analyses of Kirkby (1977) showed that MSTC could be a fundamental principle of fluvial systems. Recently, the applicability of MSTC has been supported by the computer-based studies of White et al. (1982), Wang et al. (1986), Bettess and White (1987) and Farias (1995).

Despite some success in applying the mEDR hypothesis, Yang et al. (1981) showed that it produces a constant width/depth ratio of 2, yet nearly all natural channels are very much larger than this. From the principle of virtual work or energy for a mechanical system, however, Chang (1979a, 1979b, 1980a, 1980b, 1985, 1988) proposed the hypothesis of minimum stream power $(\mathrm{mSP})$. This has received considerable attention (see, e.g., Millar and Quick, 1993, 1998; Millar, 2005), because in a variety of circumstances it has demonstrated an ability to provide a high level of prediction of both channel geometry and river channel pattern. However, Chang's mSP principle was computer derived and has not been able to identify physical causes. As a result, it has been argued conceptually that the conditions of maximum friction (Davies and Sutherland, 1980, 1983; Eaton et al., 2004), variants of minimum Froude number (Jia, 1990; Yalin and Silvia, 1999, 2000) and critical flow (Grant, 1997) are the principles controlling river channel adjustment. While each of these extremal hypotheses has, to some extent, been shown to apply to the behaviour of alluvial rivers, their selection for consideration has to date been somewhat arbitrary due to a lack of a convincing theoretical explanation for the adoption of any single one. Why would a river maximize or minimize any particular condition?

\section{LAP and the associated special equilibrium state}

The most general formulation of the LAP is expressed in the following form:

$$
\delta A=0
$$


which implies that motion tends to take a trajectory for which the action $A$, a measure of the energy of the system under study, achieves a stationary equilibrium state, as explained below.

For flow in an open channel, Huang and Nanson (2000, 2001, 2002) and Huang et al. (2002, 2004a, 2004b) have examined the applicability of the LAP and found that, due to the action of gravity, the LAP can be written as the principle of minimum potential energy. For transporting water discharge and sediment load, however, flow needs to have a certain amount of kinetic energy to achieve equilibrium. As a result, part of this minimum amount of potential energy must be converted into kinetic energy, leading the principle of minimum potential energy to be more specifically expressed as the principle of minimum (total) (specific) energy (PmE). As demonstrated by Huang et al. (2004a), PmE applies to all kinds of open channel flow: ideal frictionless or frictional flow in nonadjustable channels or flow in adjustable alluvial channels that transport sediment. In solid mechanics, minimum energy occurs when the material remains stationary. For liquids in motion, as in all the above three open channel systems, the stationary equilibrium state occurs when and where the total supplied specific energy $E$ reaches a minimum, or $E=E_{\min }$ :

$$
E_{\min }(\zeta)=\operatorname{Min}\left[E_{\mathrm{p}}(\zeta)+E_{\mathrm{k}}(\zeta)\right]
$$

subject to

$$
\varphi_{i}(\zeta)=0
$$

where $E_{\mathrm{p}}$ is the specific potential energy, $E_{\mathrm{k}}$ is the specific kinetic energy and $\varphi_{i}(\zeta)$ represents $i$ number of constraints, including continuity of fluids, flow resistance and sediment transport, all of which are functions of a geometric variable of cross-sections, $\zeta$ (width/depth ratio or depth when width is fixed).

The determination of $E_{\min }$ in Equations (3) and (4) is exactly the same as finding the minimum condition of the Hamilton function or Hamiltonian (sum of kinetic energy and potential energy), which is the most important operator of variational theorem in both classical and quantum mechanics (see, e.g., Lanczos, 1952; Dugas, 1957; Stauffer and Stanley, 1989; Kroemer, 1994). Observable from Equations (3) and (4) is that $E_{\min }$ possesses exactly the same physical meaning as the most generalized variational principle LAP, that of using the least possible amount of energy to complete a given task. This includes transporting given water and sediment loads in fluvial systems. Hence, the existence of $E_{\min }$ explains how the LAP effectively governs open channel flow.

The role of a 'stationary equilibrium' state in something as dynamic as a river is initially not intuitively obvious. In solid mechanics it can be simply illustrated by a pendulum, which has its available energy in two parts; the energy stored above a position of rest (potential energy) and that of motion (kinetic energy) (Figure 2). The perpendicular position of the pendulum is the point of 'stationary equilibrium' and acts as an 'attractor' of motion, through which the pendulum must pass and where in motion it has minimum potential energy and maximum kinetic energy. As it swings, energy is passed back and forth between these two states. When the pendulum is at rest there is only potential energy present and total energy is at a minimum $\left(E=E_{\min }\right)$. When there is excess energy in the system $\left(E>E_{\min }\right)$, the pendulum must remain in motion but, importantly, the attractor that characterizes the whole process of dynamic motion is the point of 'stationary equilibrium'. This illustrates the importance that a stationary equilibrium state (minimum energy) plays in any dynamic system where energy must obey the law of energy conservation and is being converted from one state to another (Figure 2). In a river with excess potential energy, this excess must be converted mostly to frictional kinetic energy by, for example, the development of undulating bedforms, or meandering or braiding planforms. Hence, analogous with the swinging pendulum, the stationary state in a river system with no surplus energy determines the degree of dynamic adjustment when the system has excess energy. This is detailed later in this paper.

In a river with insufficient potential energy (slope) there is no surplus energy to be consumed. This cannot be easily represented by a pendulum, because we are describing some point of minimum potential energy below the stationary central point in the arc of the pendulum. However, adjustments to a river channel can be made such that frictional energy losses are reduced and/or potential energy is increased to the point where there is the minimum energy required for the transport of the water and sediment supplied. This may involve straightening or upstream aggradation of the channel (hence steepening), or a reduction in the aspect ratio (W/D) towards a more efficient cross section. Again, the stationary equilibrium state is the attractor that determines the nature of dynamic activity in the system.

PmE has been widely applied, not just in classical mechanics, but in more complicated cases. For an example of a quantum system, electrons achieve a 'stationary' state when, even though the electrons are not stationary, the system's total energy reaches a minimum above that of minimum potential energy. As shown by Huang et al. (2004a), the stationary equilibrium state in an open channel $\left(E=E_{\min }\right)$ is where the available energy is just able to transport the fluid and sediment load. Unlike a pendulum, but as in quantum mechanics, in this situation a river is not stationary or 
unable to flow; however, the concept is the same as for solid mechanics, hence the acquired terminology. In a river when surplus energy is maximally dissipated as fiction (skin resistance) without doing any additional work, and the energy is therefore just sufficient to move the water and sediment supplied, the river will consist of a straight channel and we would say the system is 'in stationary equilibrium'. When a river dissipates most of its surplus energy as friction, but still has sufficient to do some additional work (such as moving its meander bends or reforming its braid bars and associated channels, generating internal distortion resistance to consume the surplus), then the system is like a swinging pendulum and is 'in dynamic equilibrium'. This distinction between stationary and dynamic equilibrium in rivers is very important.

\section{Clarifying the confusion of multiple extremal hypotheses}

Within the context of PmE, when a fluvial system possesses energy just equal to that of $E_{\min }$, its motion will be just sufficient to transport the imposed load. In a solid body this is the critical state for motion, such that no additional work or no work at all can be performed. This link between work and equilibrium was the basis for the proposal by Leopold and Langbein (1962) of the extremal hypotheses of minimum variance and least work. In this sense, their two hypotheses can, in origin, be regarded as the specific forms of PmE and the LAP.

When flow possesses excess energy, or $E>E_{\min }$ (where $E=E_{\mathrm{p}}+E_{\mathrm{k}}$ ), the law of energy conservation makes Equation (4) or $E_{\min }$ achievable only when the following condition is satisfied under the restriction of Equation (4):

$$
\underset{\zeta>\zeta_{\mathrm{m}} \text { or } \zeta<\zeta_{\mathrm{m}}}{E_{\text {exp }}} \rightarrow \underset{\zeta=\zeta_{\mathrm{m}}}{E_{\text {min }}}
$$

in which expended energy $E_{\text {exp }}=E-E_{\min }$ and $\zeta_{\mathrm{m}}$ represents the value of $\zeta$ at which $E_{\min }$ is achieved.

This means that when flow possesses excess energy $E_{\min }$ can be achieved only when the excess energy $E-E_{\min }$ is fully expended. Because most valleys are steeper than the gradient required for stationary equilibrium river flow, most dynamic systems behave by maximizing energy expenditure. This explains why the extremal hypotheses of maximum energy expenditure, maximum friction factor, maximum flow resistance or maximum rate of energy dissipation have each been proposed as the fundamental principle governing alluvial channel flow (see, e.g., Jefferson, 1902; Schoklitsch, 1937; Inglis, 1947; Davis and Sutherland, 1980, 1983; Huang, 1983, 1988; Abrahams et al., 1995; Lamberti, 1988; Phillips, 1991; Eaton et al., 2004). However, these extremal hypotheses are valid only if they deal specifically with the excess portion of available energy, or $E-E_{\min }$, when $E>E_{\text {min }}$.

During the process of maximizing the expenditure of excess energy, dynamic systems inevitably generate friction in proportion to their excess energy. Only when these dynamic systems are in a minimum energy state are they able to be frictionally minimal. Since friction represents energy dissipation into heat, the equivalence between PmE and minimum friction shows, as argued by the Yang group (Yang, 1971, 1987; Yang and Song, 1979; Song and Yang, 1980, 1982; Yang et al., 1981), that mEDR derived in terms of entropy theory is indeed applicable to open channel flow. However, among the many forms of $\mathrm{mEDR}$ that have been previously hypothesized, only those leading to maximum flow efficiency (MFE) (Huang and Nanson, 2000, 2001, 2002), mSP and MSTC, can be adopted. The form of mEDR identified here from laws governing open channel flow demonstrates that the principle of minimum entropy production, well developed in non-equilibrium thermodynamics, can also be applied to explain with a velocity field the behaviour of fluids at stationary equilibrium (Stauffer, 2005).

In contrast to frictionless conditions, where available energy is in the form of potential energy and kinetic energy and can be defined using the Froude number (kinetic energy over potential energy varying with depth and velocity), in flow with friction and/or sediment transport the available energy is spent overcoming friction from both the channel bed (width) and banks for a given sediment load. This means that the Froude number, based as it is on frictionless and constant-width conditions, cannot reflect accurately the way in which the available energy is expended in alluvial channel flow, and so the extremal hypotheses of two forms of minimum Froude number proposed by Jia (1990) and by Yalin and Silva $(1999,2000)$ are not appropriate in this case. However, when channel width is constrained, variation is largely with depth and velocity and, as a result, the Froude number can become a defining parameter, even if there is friction and sediment transport. Steep mountain streams are examples of this kind of vertical flow response. Because such streams possess beds of coarse gravel and boulders in the form of step pools with very high critical thresholds for bed motion, their surfaces are sufficiently rough and stable to fully expend the flow's excess energy, and critical flow occurs. This explains why in steep mountain streams energy is consumed in the vertical plane in the form of critical flow, plunge pools and standing waves rather than the lateral plane, as occurs in lower gradient streams that meander or braid (see, e.g., Simon, 1992; Abrahams et al., 1995; Grant, 1997; Tinkler, 1997a, 1997b). 


\section{Advantages of the Variational Approach for Solving River Regime Problems}

\section{River regime problems}

In terms of their geometry, alluvial rivers are self-forming and operate most effectively by moving water and sediment from their drainage basins under conditions approximating bankfull flow (Wolman and Miller, 1960). They exhibit stable channel geometries, which can be predicted with reasonable accuracy using 'regime theory' for stable canals (Lacey, 1929, 1933, 1946, 1958; Blench, 1952, 1969, 1970; Simons and Albertson, 1960) and 'hydraulic geometry' for stable river channels (Leopold and Maddock, 1953; Parker, 1979; Huang and Warner, 1995; Huang and Nanson, 1995, 1997, 1998). While these regime relationships are a response to a set of interacting factors associated with the amount of water and sediment in transport, and a range of additional factors such as local vegetation, sediment texture and regional gradients, they can be represented empirically simply and approximately in the following form:

$$
W=a Q^{0.5} ; \quad D=c Q^{0.3} ; \quad V=t Q^{0.2}
$$

where $W, D$ and $V$ are respectively the channel width, average depth and average flow velocity, and $a, c$ and $t$ are coefficients.

In stable channels with uniform boundaries, coefficients $a, c$ and $t$ in Equation (6) are determined mainly by sediment composition, but in natural rivers they are also closely related to bank vegetation, boundary roughness, slope and sediment transport (Schumm, 1960; Richards, 1982; Ferguson, 1986; Huang and Nanson, 1995, 1997, 1998, 2000; Huang and Warner, 1995; Julien and Wargadalam, 1995; Huang, 1996).

We propose that such stable channels represent a stationary equilibrium condition, where imposed water and sediment loads are transported without causing an imbalance between deposition and erosion (Mackin, 1948). This phenomenon of river regime would be highly unlikely if there were not some self-adjusting principle(s) controlling the myriad of possible combinations of geometric forms that an alluvial river could adopt.

In the channelized flow of self-adjusting streams with uniform mobile boundaries, three basic relationships define the physics of water and sediment movement; flow continuity, flow resistance and sediment flux. These can be relatively simply expressed by the following relationships:

$$
\begin{gathered}
Q=W D V \\
V=\sqrt{\frac{8}{f} g R S_{f}} \\
Q_{\mathrm{sc}} / W=c_{\mathrm{d}}\left(\tau_{0}-\tau_{\mathrm{c}}\right)^{1 \cdot 5-1 \cdot 8}
\end{gathered}
$$

where $f, g, R, Q_{\mathrm{sc}}, \tau_{0}, \tau_{\mathrm{c}}$ and $c_{\mathrm{d}}$ are the flow friction factor, gravity constant, hydraulic radius, carrying capacity of flow for sediment discharge, shear stress, critical shear stress and a coefficient related to sediment size, respectively. $S_{f}$ is the fractional slope of flow and $S_{f}=\mathrm{S}$ for uniform channel flow considered in this study.

Because there are three equations with four variables (width, depth, velocity and slope; the fifth, $\tau_{0}$ can be calculated from these), these three equations have previously been interpreted as insufficient to explain the phenomenon of river regime. As a result, two approaches have been adopted: Newtonian formulation and extremal hypothesis.

The Newtonian formulations of the problem of river regime have been performed in terms of the diffusion of turbulence on the transverse direction of flow (see, e.g., Parker, 1978a, 1978b, 1979; Ikeda, 1981; Ikeda et al., 1988; Pizzuto, 1990; Kovacs and Parker, 1994; Vigilar and Diplas, 1997, 1998). Methodologically they include three steps: (1) dividing a stream channel cross-section into many parts; (2) formulating the motion of each part as it interacts with the motion of the adjacent parts or with the boundary and (3) integrating all the parts to reveal the characteristics of the whole cross-section that result from these detailed internal interactions (Figure 3). By doing so, this type of analysis has provided very detailed interpretations of the empirically based hypothesized processes leading to the exhibition of the hydraulic geometry relations in Equation (6). However, as discussed by Phillips (1991), Knighton (1998) and Huang and Nanson (2002), this approach generally involves very complicated mathematical analyses that have not, as yet, enabled the development of a generally applicable theory for understanding flow and channel-form interactions.

On the other hand, an understanding of the physical controls of river regime has been obtained by incorporating one of a number of extremal hypotheses into Equations (7)-(9) in order to obtain mathematical closure. In comparison to the complex Newtonian formulations, this approach is much simpler; however, it has lacked a convincing physical justification. As a consequence, there has been no consensus as to which hypothesis is correct (see, e.g., Knighton, 1998). 
A

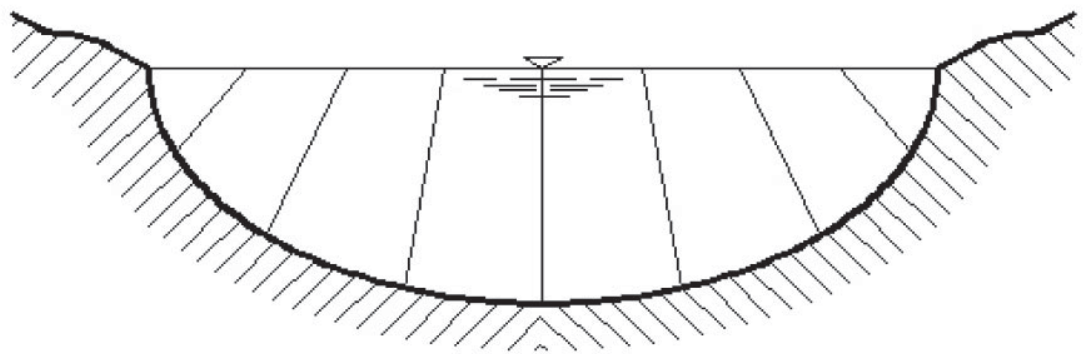

B
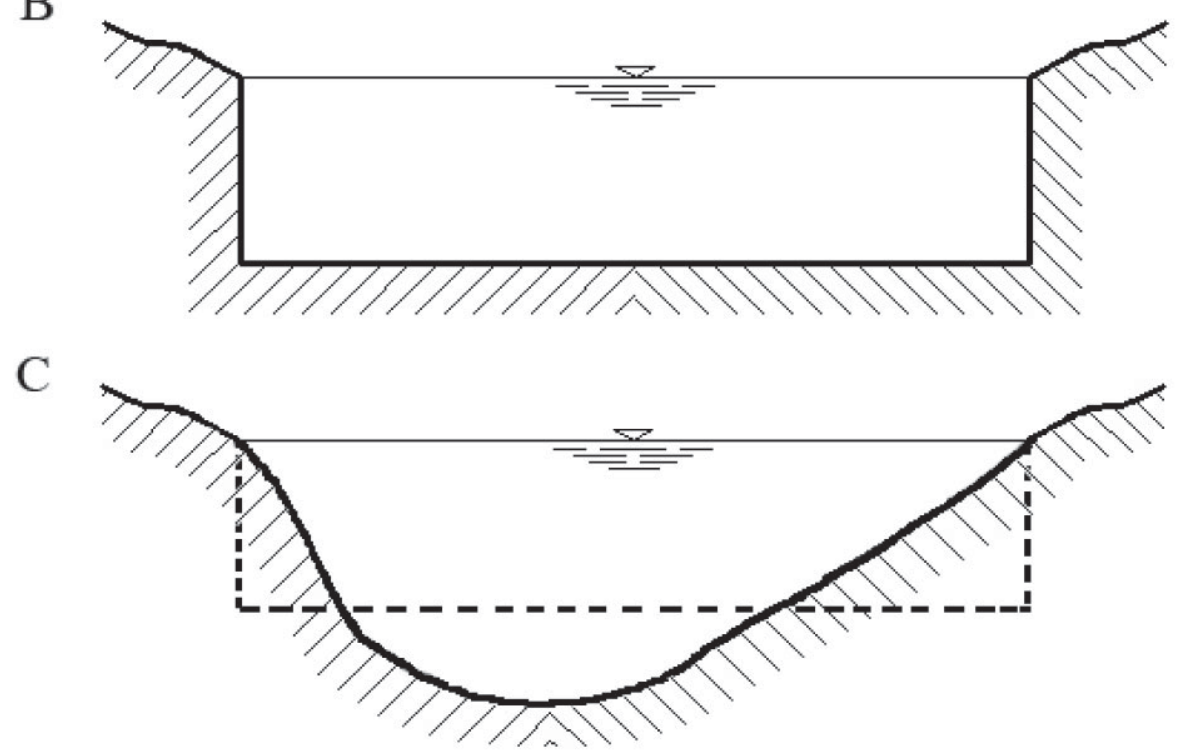

Figure 3. Conceptualization of alluvial channel cross-sectional profile: (A) Newtonian formulation of cross-sectional profile; (B) fuzzy objectification of the shape of the whole cross-section; (C) an initial rectangular cross-section and that resulting from minor natural perturbations.

\section{Advantages of fuzzy objectification and variational approach}

Recognizing the difficulties in obtaining a solution for the precise form of the profile of stream channel cross-sections as shown in the Newtonian formulations, Huang and co-workers (e.g. Huang and Nanson, 2000, 2001, 2002; Huang et al., 2002; Huang and Chang, 2006) regard the precise form of the profile as a problem with uncertainty. As a consequence, they advanced an object-orientated variational methodology in the context of fuzzy theory. Rather than seeking the precise mathematical expression of the profile of the object (channel cross-section), they introduce the channel aspect ratio $\zeta$ (width/depth) as a fuzzy variable that characterizes natural channel shape with some degree of certainty (Figure 3). In this way, a complex stream channel cross-section can be illustrated as an integration of a simple rectangular form with a minor perturbation on the boundary. This simplification can accommodate the hydraulic conditions resulting from a range of natural variations over the channel boundary. In other words, real channel cross-sections may result from the influence of natural perturbations on what would otherwise be a simple relatively wide rectangular form. Figure 3(C) shows a channel cross-section that could result from minor perturbations to an originally rectangular cross-section. Due to flow turbulence and channel boundary heterogeneity, such natural variations generally have some degree of random character. Consequently, finding the precise expression of the cross section is very difficult and, depending on the degree of detail being sought, is probably not necessary at the level of explanation and prediction of channel form often being sought.

With the fuzzy-object orientated method, they examined the effect of variable shape on the flow regime and demonstrated that, without adopting any extremal hypothesis, the phenomenon of river regime can be explained directly with the basic relationships of flow continuity, resistance and sediment (bedload) transport. This is because the 
A

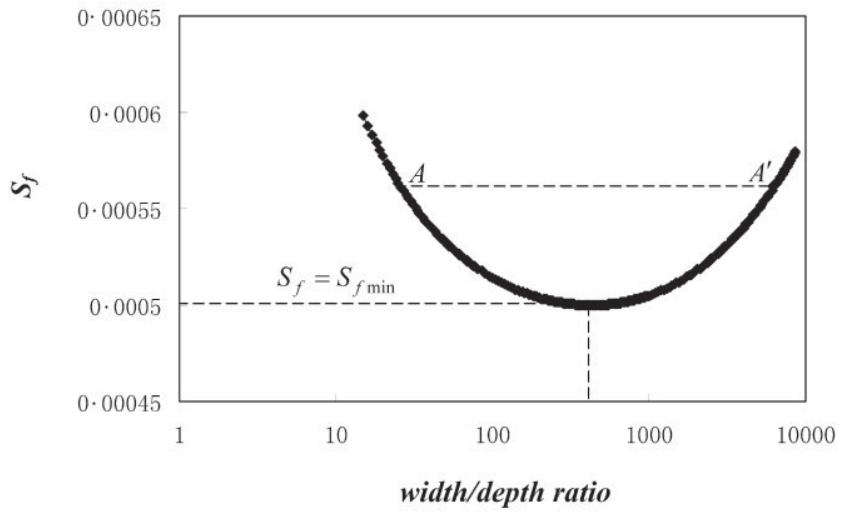

B

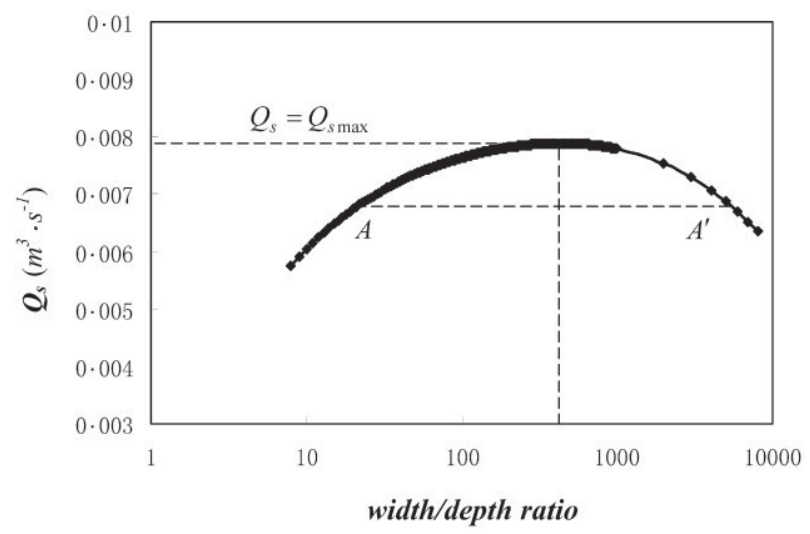

Figure 4. An example of variations in sediment transport $Q_{s}$ with changes in width/depth ratio $\zeta\left(Q=100 \mathrm{~m}^{3} \mathrm{~s}^{-1}, \mathrm{~S}_{f}=0.0005\right.$ and $d=0.3 \mathrm{~mm})$ and channel energy slope $S_{\mathrm{f}}$ with changes in width/depth ratio $\zeta\left(Q=100 \mathrm{~m}^{3} \mathrm{~s}^{-1}, Q_{\mathrm{s}}=0.0078 \mathrm{~m}^{3} \mathrm{~s}^{-1}\right.$ and $\left.d=0.3 \mathrm{~mm}\right)$ using the Myer-Peter and Müller (1948) formula. It is apparent that in most cases there are two possible dynamic equilibrium forms of channel geometry that can transport a given water and sediment load, but only at one point $\zeta=\zeta_{m}$ does a unique channel geometry occur. At this point, the total energy expenditure in the flow reaches a minimum, the stationary equilibrium state.

introduction of the channel aspect ratio $\zeta$ (width/depth) into the three basic hydraulic relations of Equations (7)-(9) can make $Q_{s}$ and $S_{f}$ functions of a single variable $\zeta$, or $Q_{s}(\zeta)$ and $S(\zeta)$ (see, e.g., Huang and Nanson, 2000, 2002). In terms of this analytical approach, Figure 4 presents an example of the variations of the two functions based on the Meyer-Peter and Müller (1948) formula for bed-load transport and the Manning-Strickler flow resistance relationship. It can be seen in this figure that in most cases there are two possible dynamic equilibrium forms of channel geometry that can transport a given water and sediment load, but only at a single point $\zeta=\zeta_{\mathrm{m}}$ does unique channel geometry occur. At this point, the total energy expenditure in the flow reaches a minimum, the stationary equilibrium state. For given water and sediment loads $Q$ and $Q_{s}$, this unique solution can be determined by minimizing the frictional slope of flow $S_{f}$ :

$$
S_{\text {fmin }}=\left.\operatorname{Min} S_{f}(\zeta)\right|_{\mathrm{d} Q=0 \cap \mathrm{d} Q_{\mathrm{s}}=0}=S_{f}\left(\zeta_{\mathrm{m}}\right)
$$

At the same point of $\zeta_{\mathrm{m}}, Q_{\mathrm{s}}$ also achieves a maximum for given $Q$ and $S_{f}$ :

$$
\left(Q_{\mathrm{sc}}\right)_{\max }=\left.\operatorname{Max} Q_{\mathrm{sc}}(\zeta)\right|_{\mathrm{d} Q=0 \cap \mathrm{d} S=0}=Q_{\mathrm{s}}\left(\zeta_{\mathrm{m}}\right)
$$

As demonstrated by Huang and co-workers, the unique solution of alluvial channel geometry mathematically derived under conditions where $S_{f}=S_{\text {fmin }}$ or $Q_{\mathrm{s}}=\left(Q_{\mathrm{s}}\right)_{\max }$ is highly consistent with the widely observed hydraulic geometry relations in Equation (6). Importantly, this demonstrates that the condition of $S_{f}=S_{\text {fmin }}$ or $Q_{\mathrm{s}}=\left(Q_{\mathrm{s}}\right)_{\max }$ is the 
product of the LAP (Huang and Nanson, 2000, 2001, 2002; Huang et al., 2002, 2004a, 2004b; Huang and Chang, 2006). Hence, the most efficient alluvial channel geometry derived is based on the condition of $S_{f}=S_{f \min }$ or $Q_{\mathrm{s}}=\left(Q_{\mathrm{s}}\right)_{\max }$ and provides a testable case for verifying the applicability of the LAP in alluvial channel flow. This demonstrates that the application of the LAP in alluvial channel flow is not a teleological proposition and it shows that, among the many extremal hypotheses suggested to explain river channel geometry, only mSP and MSTC can be regarded as the specific expressions of the LAP, the primary principle for river channel geometry. Furthermore, because the condition of mSP or MSTC quantitatively measures the status of flow efficiency, it provides a very useful way of studying and understanding the adjustment of river channel form in the situation where $S_{f}>S_{\text {fmin }}$ or $Q_{\mathrm{s}}<\left(Q_{\mathrm{s}}\right)_{\max }$, in other words where $E>E_{\text {min }}$.

While the conditions of $\mathrm{mSP}$ and MSTC inherent in basic hydraulic relations for alluvial channel flow provide a convincing physical explanation for why regular regime relations and bankfull hydraulic geometry have been exhibited in a very wide range of environments, it needs to be stressed that these outcomes, and the recent progress made by Huang and Nanson (2007) in explaining the cause of anabranching rivers in terms of the variational analytical approach advocated by Huang and co-workers, have demonstrated that the basic hydraulic relations of flow continuity, resistance and sediment transport are sufficient to explain not only the regime relations but also the dynamic forms of river channel flow. In other words, there is no need to predefine any extremal hypothesis in order to gain a proper understanding of the behaviour of river channel flow.

\section{Linear relation between shear stress and width/depth ratio - a measure of flow efficiency in alluvial channels}

Using the advantages of the variational approach, Huang and Chang (2006) investigated possible sediment transport conditions leading to river regime and show that, at the point when $S_{f}=S_{\text {fmin }}$ or $Q_{\mathrm{s}}=\left(Q_{\mathrm{s}}\right)_{\max }$, flow in straight alluvial channels yields a linear relationship between shear stress $\tau_{0}$ and width/depth ratio $\zeta$ for different flow regimes, including flat bed, lower and upper flow regimes:

$$
\frac{\tau_{0}-\tau_{\mathrm{c}}}{\tau_{\mathrm{c}}}=0 \cdot 3\left(\zeta-\zeta_{\mathrm{c}}\right)
$$

where $\zeta_{\mathrm{c}}$ is the optimum width/depth ratio when $\tau_{0}=\tau_{\mathrm{c}}$ or $Q_{\mathrm{s}}=0$.

As a consequence, a scale invariant number emerges, denoted as $H$ and expressed as the ratio of the relative increment of shear stress to the increment of width/depth ratio:

$$
H=\frac{\Delta \tau_{0}}{\Delta \zeta}=0 \cdot 3
$$

This is the outcome of the physical mechanism whereby flow in a straight alluvial channel achieves the stationary equilibrium state for sediment transport. As noted in the transport formula of Equation (9), sediment transporting capacity $Q_{\text {sc }}$ for a given sediment size is a function of both channel width $W$ and flow shear stress $\tau_{0}$. There exists a complex quasi-parabolic (rising and falling) relationship between average shear stress $\tau_{0}$ and the aspect ratio $\zeta$, while a simple monotonic relationship is maintained between channel width $W$ and $\zeta$ (Huang and Nanson, 2000, 2002). Because, as shown in Equation (9), $Q_{\mathrm{s}}$ is in a complex relationship with $\tau_{0}$ and $W$, $\tau_{0}$ plays a major role in transporting sediment load in narrow deep channels only, quantitatively resulting in $H>0 \cdot 3$. In wide shallow channels, Equation (9) shows that the role of $W$ outweighs that of $\tau_{0}$, yielding $H<0 \cdot 3$. Only in the ideal case where the roles of $\tau_{0}$ and $W$ are closer to equal within a channel that is neither very wide and shallow nor very narrow and deep does $H=0 \cdot 3$ occur. Huang and Chang (2006) demonstrate that the most efficient alluvial channel geometries are mathematically derived where $H=0.3$ and are highly consistent with the most commonly observed regime relations and downstream hydraulic geometry relations.

The $H$ number can be regarded as a supplement to the widely applied Froude number $F$ in open channel hydraulics, which measures the flow's kinetic energy over potential energy (varying with depth and velocity) in the following form:

$$
F=\frac{V}{\sqrt{g D}}=1 \cdot 0
$$

The physical meaning of $F$ is that when frictionless open channel flow is constrained laterally (constant channel width), making $F \neq 1 \cdot 0$, it tends to transfer excess potential energy to kinetic energy, or vice verse, on a vertical plane (channel depth). In the situation of $F=1.0$ the energy of flow reaches a critical level, at which no energy conversion 
is possible and below which the flow cannot move as an entity (Henderson, 1996). As Huang et al. (2004a) demonstrated, the situation of $F=1.0$ is also the product of the LAP under frictionless and constant width conditions.

The $H$ number measures the available energy spent overcoming friction from both the channel bed and banks for a given sediment load, and the situation of $H=0.3$ means that, as stated earlier, the energy of alluvial channel flow reaches a minimum level for transporting a given water and sediment load. Given that the two numbers come from the same physical root of the LAP, and because of the role that $F$ number plays in open channel flow (as detailed by Henderson, 1966), the $H$ number can be regarded as a quantitative index for directly measuring the stability and the potential development of complex channel forms in situations where $H \neq 0 \cdot 3$. These include determining the spacing of pools and riffles and meander wavelengths with increasing channel width, and determining step steepness with increasing bed slope in step-pool systems. The study by Huang and Chang (2006) also demonstrates that the $H$ number provides a basis for assessing the applicability of previously developed semi-theoretical sediment transport formulae. A detailed investigation of the process by which the $H$ number enables the prediction of complex channel forms is currently underway, as is the possibility of developing a universally applicable sediment transport formula based on its linear characteristic.

\section{River Channel Planform: Causes and Modes of Development}

\section{Physical cause for river-channel planform development}

The principle of least action should result in self-adjusting alluvial rivers all looking similar. While there is considerable consistency in terms of hydraulic geometry, channel planform can vary widely and include straight, braiding, meandering and anabranching types. As discussed earlier, valley gradient $\left(S_{\mathrm{V}}\right)$ is usually not directly a product of the contemporary river but is inherited and therefore acts as an independent or exogenous variable. Consequently, there is almost always a discrepancy between $S_{\mathrm{V}}$ and the minimum energy slope $S_{\text {fmin }}$ required for transporting an imposed water discharge $Q$ and sediment load $Q_{\mathrm{s}}$ in a straight, maximally efficient, single-thread channel. For given $Q$ and $Q_{\mathrm{s}}$ from upstream, the river must adjust $S_{\text {fmin }}$ as a hydraulic variable, and Huang and Nanson $(2000,2001,2002)$ showed that $S_{\text {fmin }}$ can be determined from the following relationship:

$$
S_{\mathrm{fmin}} \propto Q_{\mathrm{s}}^{0.708 \sim 0.522} Q^{-(0.788 \sim 0.702)} \propto\left(\frac{Q_{\mathrm{s}}}{Q}\right)^{0.708 \sim 0.522} Q^{-(0.080 \sim 0.180)}
$$

Because $S_{\mathrm{V}}$ and $S_{\text {fmin }}$ are derived from different processes, there are three possibilities: (1) $S_{\mathrm{V}}=S_{\text {fmin }}$; (2) $S_{\mathrm{V}}>S_{\text {fmin }}$ and (3) $S_{\mathrm{V}}<S_{\text {fmin }}$. In the highly unusual situation of $S_{\mathrm{V}}=S_{\min }$, the valley gradient is exactly that required to transport the imposed water and sediment. The channel will be straight and laterally stable, with a self-formed bankfull geometry that is in stationary equilibrium and uses energy in the most efficient way. Such systems have been assumed to be single thread and have been described theoretically using the equivalent conditions of $E_{\min }$, such as mSP, MSTC and MFE (see, e.g., Chang, 1979a, 1980a, 1980b, 1988; White et al., 1982; Huang and Nanson, 2000, 2001, 2002).

In contrast, when $S_{\mathrm{V}}>S_{\text {fmin }}$ then energy in the system is more than that required and this surplus must be shed in order for the system to achieve stable equilibrium. In such a valley, as demonstrated in the analysis of basic hydraulic relations, there are two types of channel capable of consuming the excess energy in a straight single-thread alluvial channel system (e.g. points A and $\mathrm{A}^{\prime}$ on both $Q_{\mathrm{s}}-$ and $S_{\mathrm{f}}$-width/depth curves in Figure 4) - very wide and shallow or very narrow and deep. Such wide or narrow sections are, however, only theoretical possibilities derived from the endogenous hydraulic relations and, therefore, because of possible boundary erosion and/or sediment deposition, neither section may be able to remain stable in a particular alluvial setting.

When $S_{\mathrm{V}}<S_{\text {fmin }}$, stationary equilibrium cannot be achieved by simple expenditure of excess energy. This is because of an insufficient supply of energy to move all the sediment supplied from upstream. However, besides valley gradient, other exogenous factors play a role in the development of self-adjusting river channel patterns by altering endogenous conditions. These include valley width and sinuosity as well as the river's exogenous (non-mobile) boundary conditions (i.e. riparian vegetation, alluvium from prior flow regimes, colluvium, glacial or lacustrine deposits, peat, bedrock etc.). The combined effects of both endogenous and exogenous factors on the formation of river channel patterns have been quantified with several integrated models (see, e.g., Schumm, 1977; Bettess and White, 1983; Wang and Zhang, 1989; Schumm and Winkley, 1994; Eaton et al., 2004; Millar, 2005). While most of these previous models have focused largely on the effect of valley slope, Huang and Nanson (2007) present a detailed mathematical analysis of the effects of the other exogenous factors, particularly non-uniform channel boundaries confined by riparian vegetation, on the development of anabranching and braiding rivers. 


\section{Modes of river channel planform development}

Where $S_{\mathrm{V}}>S_{\text {fmin }}$. As detailed in the study by Huang et al. (2004a), in all types of open channel where $S_{\mathrm{V}}>S_{\text {fmin }}$, flow is essentially driven by gravity and tends to rapidly achieve a stationary equilibrium state (LAP) by maximizing the expenditure of any excess energy. As argued by Grant (1997), the behaviour of rivers in hydraulically steep valleys is governed by the Froude number $F$ defined in Equation (14). Indeed, step-pool systems in mountain streams illustrate this kind of vertical adjustment (see, e.g., Abrahams et al., 1995).

However, most alluvial rivers are located in relatively gently sloping wide valleys where they can expend excess energy laterally. This is because steep narrow valleys offer considerable vertical space for performing energy transfers, whereas gentle wide alluvial valleys are correspondingly limited vertically but have considerable lateral space. We argue that this implies that the LAP effectively governs the adjusting process for minimizing work by consuming excess energy on the most available plane.

The expenditure of excess energy in relatively gently sloping wide valleys can be achieved by adjusting channel slope, width, depth, sinuosity and number of braid bars and associated channels. Although theoretically it is possible to expend surplus energy by adjusting all of these variables at the same time, rivers in reality seem to adjust only one or two in each case, resulting in the widely observed typical river styles. This selective simplicity may also be a least action process for expending a river's excess energy.

Over a valley gradient that is not steep enough to adopt a step-pool system, a braided channel pattern will expend excess energy sufficiently rapidly by widening and frequently forming and reworking flow-resisting bars. In an environment with lower gradients, meandering channels expend excess energy in a more modest and uniform way (Langbein and Leopold, 1966). Over even lower gradients, but where energy is still in excess, it is possible to consume this surplus by forming multiple channels (anabranching) without adjusting channel gradient (Huang and Nanson, 2007). This may occur where the channel boundary is well vegetated and therefore too resistant to allow meanders to readily form and reduce gradients.

Where $S_{\mathrm{V}}<S_{\text {fmin }}$. Because $S_{\text {fmin }}$ represents the minimum amount of energy demanded by flow in a straight singlethread alluvial channel transporting an imposed water and sediment load without causing deposition, the situation of $S_{\mathrm{V}}<S_{\text {fmin }}$ means that such systems are not in equilibrium. However, as discussed above, slope is just one exogenous factor. Nanson and Knighton (1996) hypothesized that in conditions where $S_{\mathrm{V}}$ is only slightly below $S_{\text {fmin }}$ equilibrium could be achieved with a reduction in $W / D$ caused by cohesive well vegetated banks and no increase in slope. Nanson and Huang (1999) and Huang and Nanson (2007) have mathematically modelled such conditions, and Jansen and Nanson (2004) physically modelled them and demonstrated the relative efficiency of anabranching compared to single-thread reaches in Magela Creek in northern Australia. This means that in situations where $S_{\mathrm{V}}<S_{\text {fmin }}$ some rivers can achieve stable equilibrium, not by increasing slope, but by reducing $W / D$. Anabranching is relatively common on straight low gradient rivers in Australia, a low gradient continent where increasing channel slope is barely an option but where the formation of islands or ridges stabilized by well adapted riparian vegetation can reduce W/D ratios (Tooth and Nanson, 1999, 2000; Wende and Nanson, 1998; Jansen and Nanson, 2004; Huang and Nanson, 2007). However, as with braided and meandering rivers, not all anabranching rivers achieve stable equilibrium, the Columbia River in Canada being the most studied example (Smith and Smith, 1980; Makaske, 2001; Tabata and Hickin, 2003; Abbado et al., 2005).

Where $S_{\mathrm{V}}<S_{\text {fmin }}$, aggradation can also result in unstable braided and meandering patterns, characterized by what have been termed wandering rivers (see, e.g., Chang, 1979b; Bettess and White, 1983; Desloges and Church, 1989; Knighton, 1998). From the point view of energy expenditure, however, only braided rivers that result from an excess valley slope are capable of rapidly achieving stable equilibrium. Unstable braided, anabranching or wandering planforms of rivers with gradients too low to achieve stability by adjusting their $W / D$ will presumably await further accretion and steepening and the resulting increase in potential energy. In reality, however, increasing the gradient along a substantial length of river valley by accretion would require the deposition of a vast quantity of valley fill, its depth increasing upstream. Almost everywhere, alluvial rivers adjust far more rapidly and simply than this.

In terms of the possible energy levels of flow, effects of exogenous factors and using valley gradient $S_{V}$ to roughly characterize these levels, a synopsis of the development modes of river step-pools and channel patterns can be qualitatively presented as

$S_{\mathrm{V}} \gg \gg S_{\text {fmin }}$ : vertically dominated energy expenditure - step-pool channels;

$S_{\mathrm{V}} \gg S_{\text {fmin }}$ : vertically and laterally mixed energy expenditure - stable braided channels;

$S_{\mathrm{V}}<S_{\text {fmin }}$ : (1) slope dominated energy expenditure - stable meandering rivers;

(2) width/depth dominated energy expenditure - stable anabranching rivers;

$S_{\mathrm{V}}=S_{\text {fmin }}$ : straight single-thread channels with a uniform boundary; 
$S_{\mathrm{V}}<S_{\text {fmin }}$ : stable anabranching channels with non-uniform boundaries confined by vegetation; $S_{\mathrm{V}}<<S_{\text {fmin }}$ : aggrading braiding, meandering, anastomosing, and wandering unstable channels.

These different slope and energy related states are represented diagrammatically in Figure 5. However, the concept represented in Figure 4 of equilibrium adjustment based on both slope and W/D ratio, and that in Figure 5 based largely on slope, can be visualized as in Figure 6 by modifying the classic Lane (1955) diagram for a channel in dynamic (and mass-balance) equilibrium. It illustrates that, for a channel to achieve this equilibrium condition, water discharge must operate under conditions with not only an adjustable slope, but also an adjustable W/D ratio. However, it also illustrates the stationary equilibrium state; this is where slope is at a minimum (furthest to the left on the slope scale in Figure 6) and the W/D ratio acquires the single value in Figure 4 that enables $Q_{\mathrm{s}}$ to achieve its maximum equilibrium value (furthest to the right on the $W / D$ scale). Importantly, Figure 4 illustrates adjustment conditions for

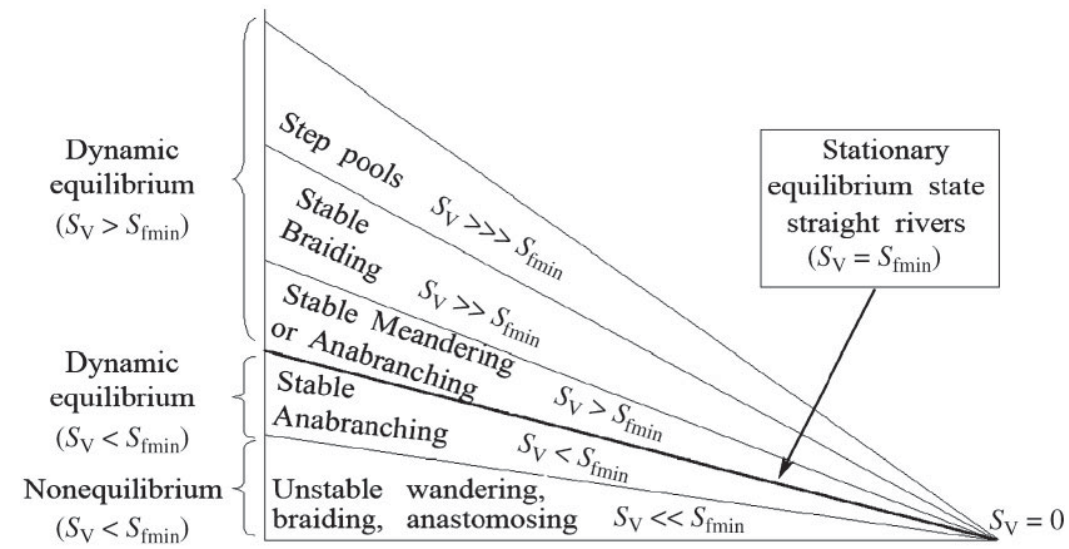

Figure 5. Schematic diagram of river channel patterns in relation to valley slope $S_{\mathrm{V}}$. The vertical axis is elevation, and the horizontal is distance, so the sloping lines represent proportional valley gradients.

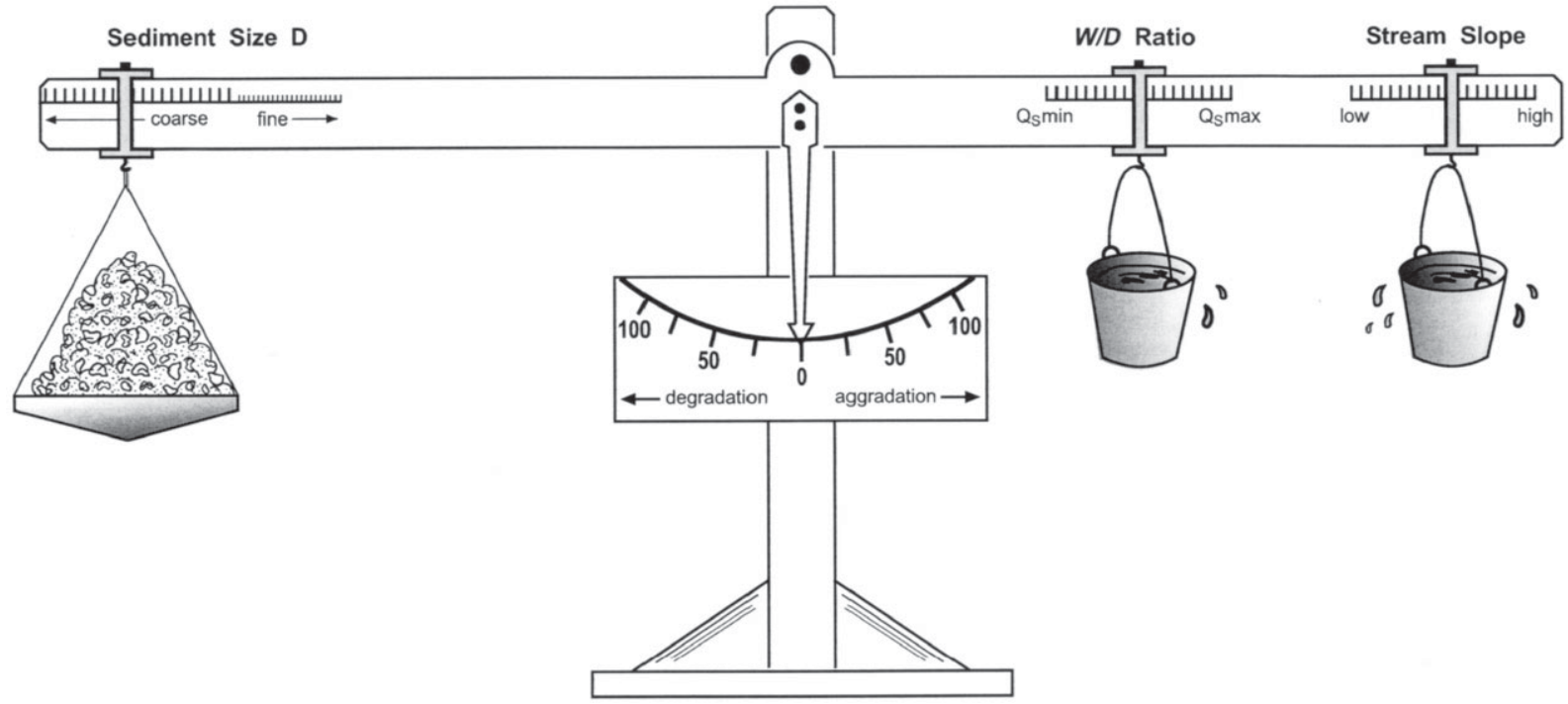

Figure 6. The interaction between stream discharge (represented in the buckets) and sediment load (represented on the pan) is the basis for the classic diagram proposed by Lane (1955) to illustrate mass-balance equilibrium in a slope-adjustable stream. Here we have modified Lane's diagram to incorporate the complex relationship in Figure 4 that shows that, for a channel to achieve mass-balance equilibrium, water discharge must operate in conditions with not only an adjustable slope but also an adjustable W/ $D$ ratio. Changes in this ratio are expressed here in terms of $Q_{s}$ because, as shown in Figure 4, in a channel with excess slope, as slope declines an equilibrium channel can have two very different values of WID. Only at a minimum slope (the right bucket having moved furthest to the left) will WID ratio achieve the single value that enables $Q_{s}$ to achieve its maximum equilibrium value (the stationary equilibrium state) (the left bucket having moved furthest to the right). 
various equilibrium states on the curve only in channels with an initial energy surplus, whereas both Figures 5 and 6 imply that channels having an initial energy deficit can reach a stationary equilibrium state as long as this is an achievable condition within the range of possible slopes and $W / D$ ratios. This has been illustrated in a numerical model by Huang and Nanson (2007), where particular W/D ratios can be imposed by exogenous variables, such as confining bank vegetation, to obtain values other than those achievable in a fully unconstrained self-adjusting system such as is represented by Figure 4. Brooks and Brierley (2002, p. 364) have described a form of dynamic equilibrium they term mediated equilibrium, whereby channels remain stable '- as long as the mediating influences of riparian vegetation and wood are retained as critical controls on system functioning'. In other words, channels lying near but below the lowest point of the curve in Figure 4(A) (and therefore near but above the highest point of the curve in Figure 4(B), or just below the stationary equilibrium line in Figure 5) can fluctuate (adjust) until they obtain a stationary equilibrium state. The next section examines how oscillating conditions can lead iterative adjustments towards this state.

\section{Iterative Adjustment and Channel Evolution - Survival of the Most Stable}

While the LAP provides a convincing physical explanation of the stationary equilibrium state in rivers, two questions need to be addressed. The first relates to a stationary equilibrium state. In terms of the stability concept defined in static mechanics, a system is normally in one of three equilibrium states; stable, neutral or unstable (Figure 1). While the stationary equilibrium in a fluvial system is not defined within the context of static mechanics, there must be a process that converts the stationary equilibrium to the stable state. The second question is how the direction of change towards such a particular stable state is achieved. It is important to establish that a river adopting an extreme position, such as PmE or the LAP, is not a teleological proposition - one that is controlled by some ultimate objective involving 'intended' efficiency. Alluvial rivers in equilibrium are remarkably stable. Those with excess gradient can expend the excess energy relatively simply via friction (heat), often braiding in steep valleys and meandering in less steep ones (Equation (16)) (Bettess and White, 1987; Huang et al., 2004a). When under-supplied with energy (over-supplied with sediment), sinuous channels can straighten and thereby steepen. If already relatively straight, wide shallow channels can deposit some of their excess sediment in the riparian vegetation along their banks and thereby create a narrower more efficient geometry, or if this is not possible the only option is the long term process of wholesale valley-floor accretion and overall steepening.

Alluvial rivers can be regarded as iterative systems. That is, they are subject to numerous repeating changes, all of which are responses to physical laws that control a myriad of complex possible changes. Non-directional iterative systems are those that can change seemingly randomly, but here we define directional iterative systems as those where the change in a particular direction is more probable than are changes in other directions. At bankfull or other channelforming discharges, such changes (erosion, transportation and deposition) take place both spatially and temporally over a mobile boundary. Some will produce more stable conditions and therefore less change and others will cause greater instability and greater change. At some locations in the same reach of a channel, sediment load will be in excess and deposition will occur, while at other locations energy will be in excess, leading to erosion. If the stationary equilibrium state lies within the range of potential conditions that the system can achieve, and this is an important proviso, then this state will act as an attractor and directional iterative change will ultimately locate it, as shown in Figure 2. If stability lies outside this range, then the system will move towards it but remain to some degree unstable or even chaotic because then a strange attractor may come into action (Gleick, 1988).

The frequency and magnitude of change in a system are a function of its degree of instability, in other words its departure from stationary equilibrium. Consequently, the most initially unstable systems will change most frequently and remain profoundly unstable for only a short period of time, and changes will proceed more slowly as they approach stationary equilibrium. Changes to more stable conditions will outlast those that lead to less stable conditions. By way of an example, if the chance growth of a tree on a river bank decreases the cross sectional area and reduces the stability of the section, then erosion will either remove the tree or enlarge the channel nearby. The result is some sort of change. Alternatively, if the addition of a tree increases the efficiency and hence stability of the section, then there is a reduced chance of the section changing in response.

If stability is the most probable condition, then why do not all rivers become completely stable? There are a number of interrelated reasons. First, due to imposed conditions, stationary equilibrium may be beyond the operational range of a particular river, in which case it will approach such a condition but not achieve it. Second, iterative change will result from energy being expended at very many points in the system, and that energy is only available at each point at a certain rate. As a consequence, a multiplicity of changes in a large system, such as a reach of river, will take a 
certain amount of time that will depend on energy availability. Third, most rivers have a fluctuating discharge as well as other changing variables including bank collapses, log or ice jams etc. Consequently, at any point the energy levels and resulting work being done are not constant. What may be stable at one time at one location may not be so some time later. Fourth, an unstable part of the system (e.g. a scour channel, a knickpoint or a depositing bar) may diffuse unstable conditions elsewhere into a previously stable part of the system. In other words, instability can sometimes propagate itself intensely for a short period of time (e.g. at a small scale bursting eddies on a river bed, or at a larger scale a meander cut-off). Finally, it appears that natural dynamic systems exhibit a certain degree of constant low level instability - they approach stability but do not completely achieve it. Where bed material is being transported in a channel, sediment ripples, dunes, bars and even sediment slugs are illustrative of ongoing localized transport instability, such that a river transporting bed sediment will never be a completely stable system. This is why alluvial rivers remain to some extent dynamic and not completely static systems.

Changes in a river channel are in some ways analogous to evolutionary changes in an organism. Organisms undergo innumerable iterative genetic changes (mutations). Under stable environmental conditions, if organisms are well adjusted to prevailing conditions, then few if any such mutations are sufficiently advantageous to be successfully adopted phenotypically. However, during periods of considerable environmental change organisms are no longer so well adjusted to prevailing conditions and the same rate of mutation can lead to rapid evolution with phenotypic changes, resulting in their becoming more in balance with the new conditions. In other words, the iterative changes that are successful reflect a directional change towards an organism more suitably adjusted to its environment. Similarly, a river channel under stable conditions will experience iterative changes, but stability is self-perpetuating and mitigates development of a less-stable system. However, if a river is subject to a dramatic change and destabilizes, subsequent iterative activity in the system will cause it to make directional changes towards the most stable system possible within the context of the newly imposed conditions. Just as the evolution of organisms is not a teleological proposition, nor is iterative change in an alluvial channel. The ultimate determinant of biological evolution is survival of the fittest, with the 'fittest' individual adopting a position of greatest stability in a stable environment (long term survival with relatively little change). The comparable driver in fluvial geomorphology is the longevity of the most stable, transport-efficient, non-erosional components of the system relative to the less stable, depositional or erosional components: in other words, survival of the most stable.

\section{Conclusions}

Over the past 40 years or so, the behaviour of fluvial systems has been explained with analogies to thermodynamic systems and by empirical intuition and complicated Newtonian formulations. Although the energy-based variational principle of least action has been shown to be a very successful scheme for explaining natural phenomena in both classical and modern physics, it received no attention in geomorphology until recent studies by Huang and Nanson (2000, 2001, 2002), Huang et al. (2002, 2004a) and Huang and Chang (2006).

This recognition of the applicability of the LAP in geomorphology yields three important advances. First, it provides a convincing physical explanation of the equilibrium state in which the LAP occurs. Since the LAP characterizes the special stationary equilibrium or stable equilibrium state and can be specifically defined with the minimum level of energy $\left(E_{\min }\right)$ demanded by the flow for carrying its water and sediment loads, three scenarios of alluvial channel flow are generally identifiable in terms of the difference between available energy $(E)$ and $E_{\min }$ : (1) $E<E_{\text {min }}$; (2) $E=E_{\min }$ and (3) $E>E_{\min }$. It is a rare case when $E=E_{\min }$; however, $E_{\min }$ or the LAP governs the direction of the energy expenditure in a river. In the case $E>E_{\min }, E_{\min }$ can be achieved when the surplus energy $E-E_{\min }$ is maximally expended. This helps clarify confusion over the applicability of numerous maximum-minimum hypotheses proposed based on analogies with thermodynamic systems and empirical intuition. In the case of $E<E_{\min }$, however, flow will be in a non-equilibrium state. How the LAP governs flow and river evolution in this state is not yet clear, albeit that the changes will be iteratively driven towards a more-probable stable state rather than a less-probable unstable one.

Second, the LAP presents a more straightforward and simpler object-orientated fuzzy method for solving river regime problems. For a long time, this problem has been pursued either with very complicated Newtonian formulations that have resulted in limited explanation, or with simple qualitative or computer-based extremal hypotheses with doubt over their theoretical basis and applicability. In contrast, the much simpler variational method tackles the uncertainty associated with determining the precise profile of the alluvial channel cross-section by incorporating a channel shape factor, the width/depth ratio, into basic flow relations. As a consequence, a purely mathematical solution for the river regime problem is obtained within the context of the LAP. Importantly, this variational method has led to the discovery of a linear characteristic inherent in the generally nonlinear alluvial channel flow and consequently defines a scale independent number $H$ presented in Equation (15). This number provides a basis for assessing the applicability of 
previously developed semi-theoretical sediment transport formulae. It can also be used to assess whether alluvial channel flow uses energy in the most efficient way and is therefore in a state of stationary equilibrium.

Third, this study demonstrates that river channel planforms are the product of the interactions between endogenous and exogenous factors. Within the context of the complex interactions, several typical modes of river channel planform that are related to the adjustment of one dominant endogenous variable in each mode can be identified. When the level of available energy is particularly high, vertical adjustment (channel depth) is the dominant adjusting form, leading to the formation of step-pool systems. When the level of available energy is low, lateral adjustment (channel slope) can be a dominant form, resulting in meandering or straight rivers. When the level of available energy is not so low as to form meandering rivers, but not so high as to form step-pool systems, channel widening could occur, yielding stable braiding rivers. In the situation where there is insufficient energy to move the supplied sediment in a straight, wide, single channel, deposition can cause a reduction in channel width, sometimes through the formation of anabranches, with a resulting increase in flow efficiency and the attainment of stationary equilibrium.

Finally, this study describes rivers as directional iterative systems where stable equilibrium offers the least opportunity for change and is therefore the attractor state and the most probable condition.

\title{
Abbreviations
}

$\begin{array}{ll}\text { LAP: } & \text { least action principle } \\ \text { MFE: } & \text { maximum flow efficiency } \\ \text { MSTC: } & \text { maximum sediment transport capacity } \\ \text { mEDR: } & \text { minimum energy dissipation rate } \\ \text { mSP: } & \text { minimum stream power } \\ \text { PmE: } & \text { principle of minimum (total) (specific) energy }\end{array}$

\section{Symbols}

\author{
$\gamma: \quad$ specific weight of water \\ $\Omega: \quad$ stream power \\ $Q: \quad$ water discharge \\ $S: \quad$ channel slope \\ $S_{f}: \quad$ frictional slope of flow \\ $S_{\text {fmin }}: \quad$ minimum frictional slope of flow \\ $S_{\mathrm{V}}: \quad$ valley slope \\ $E: \quad$ total specific energy \\ $E_{\mathrm{p}}: \quad$ specific potential energy \\ $E_{\mathrm{k}}: \quad$ specific kinetic energy \\ $E_{\min }: \quad$ minimum total energy \\ W: channel width \\ $D: \quad$ average channel depth \\ $V: \quad$ average flow velocity \\ $f$ : $\quad$ flow friction factor \\ $g$ : $\quad$ acceleration due to gravity \\ $R: \quad$ hydraulic radius \\ $Q_{\mathrm{s}}: \quad$ sediment discharge \\ $Q_{\text {sc }}: \quad$ sediment discharge carrying capacity \\ $Q_{\text {s max }}: \quad$ maximum sediment discharge carrying capacity \\ $\tau_{0}: \quad$ shear stress \\ $\tau_{\mathrm{c}}: \quad$ critical shear stress \\ $c_{\mathrm{d}}: \quad$ coefficient related to sediment size in sediment transport formula \\ $\zeta: \quad$ width/depth ratio $(W / D)$ \\ $\zeta_{c}: \quad$ optimum width/depth ratio \\ $\zeta_{\mathrm{m}}: \quad$ value of $\zeta$ at which $E_{\min }$ is achieved \\ $H: \quad$ dimensionless number defined in Equation (13) \\ F: $\quad$ dimensionless Froude number defined in Equation (14).
}




\section{References}

Abbado D, Slingerland R, Smith ND. 2005. Origin of anastomosis in the upper Columbia River, British Columbia, Canada. Special Publication of International Association of Sedimentologists 35: 3-15.

Abrahams A, Li G, Atkinson JF. 1995. Step-pool streams: adjustment to maximum flow resistance. Water Resources Research 31: 25932602.

Bagnold RA. 1966. An Approach to the Sediment Transport Problem from General Physics, US Geological Survey Professional Paper 422-I.

Bettess R, White WR. 1983. Meandering and braiding of alluvial channels. Proceedings of the Institution of Civil Engineers, Part 2, London 75: $525-538$.

Bettess R, White WR. 1987. Extremal hypotheses applied to river regime. In Sediment Transport in Gravel-Bed Rivers, Thorne CR, Bathurst JC, Hey RD (eds). Wiley: New York; 767-789.

Blench T. 1952. Regime theory for self-formed sediment-bearing channels. Transaction of ASCE 117: 383-408.

Blench T. 1969. Mobile-Bed Fluviology. University of Alberta Press: Edmonton.

Blench T. 1970. Regime theory design of canals with sand beds. Journal of Irrigation and Drainage Division, ASCE 96(IR2): $205-213$.

Bracken LJ, Wainwright J. 2006. Geomorphology and equilibrium: myth and metaphor? Transactions of the Institute of British Geographers 31: 167-178.

Brooks AP, Brierley GJ. 2002. Mediated equilibrium: the influence of riparian vegetation and wood on the long-term evolution and behaviour of a near pristine river. Earth Surface Processes and Landforms 27: 343-367.

Brown LM. 2005. Feynman's Thesis: a New Approach to Quantum Theory. World Scientific: Hackensack, NJ.

Brown LM, Rigden JS. 1993. 'Most of the Good Stuff' - Memories of Richard Feynman. American Institute of Physics: New York.

Chang HH. 1979a. Geometry of rivers in regime. Journal of the Hydraulics Division, ASCE 105: 691-706.

Chang HH. 1979b. Minimum stream power and river channel patterns. Journal of Hydrology 41: 303-327.

Chang HH. 1980a. Stable alluvial canal design. Journal of Hydraulics Division, ASCE 106: 873-891.

Chang HH. 1980b. Geometry of gravel streams. Journal of the Hydraulics Division, ASCE 106: 1443-1456.

Chang HH. 1985. Design of stable alluvial canals in a system. Journal of Irrigation and Drainage Engineering, ASCE 111: 36-43.

Chang HH. 1988. Fluvial Processes in River Engineering. Krieger: Florida.

Chow VT. 1959. Open-Channel Hydraulics. McGraw-Hill: New York.

Church M. 1992. Channel morphology and typology. In The Rivers' Handbook: Hydrological and Ecological Principles, Calow P, Petts GE (eds). Blackwell: Oxford; 126-143.

Davis TRH, Sutherland AJ. 1980. Resistance to flow past deformable boundaries. Earth Surface Processes and Landforms 5: $175-179$.

Davis TRH, Sutherland AJ. 1983. Extremal hypotheses for river behaviour. Water Resources Research 19: 141-148.

Desloges JR, Church MA. 1989. Wandering gravel-bed rivers. Canadian Geographer 33: 360-364.

Dugas R. 1957. A History of Mechanics, Maddox JR (transl.). Routledge and Kegan Paul: London.

Eaton BC, Church M, Millar RG. 2004. Rational regime model of alluvial channel morphology and response. Earth Surface Processes and Landforms 29: 511-529.

Farias HD. 1995. Physical and mathematical modelling of alluvial channels in regime. Proceedings of the XXVIth Congress of the International Association for Hydraulic Research, Vol. 1. Telford: London; 348-353.

Ferguson RI. 1981. Channel form and channel changes. In British Rivers, Lewin J (ed.). Allen and Unwin: London; 90-125.

Ferguson RI. 1986. Hydraulics and hydraulic geometry. Progress in Physical Geography 10: 1-31.

Gilbert GK. 1877. Report on the Geology of the Henry Mountains. US Geological Survey - Rocky Mountain Region: Washington, DC.

Gleick J. 1988. Chaos - Making a New Science. Sphere: London.

Goldstein H. 1950. Classical Mechanics. Addison-Wesley: Reading, MA.

Grant GE. 1997. Critical flow constrains flow hydraulics in mobile-bed streams: a new hypothesis. Water Resources Research 33: 349-358.

Griffiths GA. 1984. Extremal hypotheses for river regime: an illusion of progress. Water Resources Research 20: 113-118.

Henderson FM. 1996. Open channel flow. Macmillan, Old Tappon, New Jersey.

Huang HQ. 1996. Discussion: alluvial channel geometry: theory and applications. Journal of Hydraulic Engineering, ASCE 122: 750751.

Huang HQ, Chang HH. 2006. Scale independent linear behaviour of alluvial channel flow. Journal of Hydraulic Engineering, ASCE 132: 722-730.

Huang HQ, Chang HH, Nanson GC. 2004a. Minimum energy as the general form of critical flow and maximum flow efficiency and for explaining variations in river channel pattern. Water Resources Research 40: W04502. DOI: 10.1029/2003/WR002539, 1-13

Huang HQ, Nanson GC. 1995. On a multivariate model of channel geometry. Proceedings of the XXVIth IAHR Congress, Vol. 1. Telford: London; 510-515.

Huang HQ, Nanson GC. 1997. Vegetation and channel variation; a case study of four small streams in southeastern Australia. Geomorphology 18: $237-249$.

Huang HQ, Nanson GC. 1998. The influence of bank strength on channel geometry: an integrated analysis of some observations. Earth Surface Processes and Landforms 23: 865-876.

Huang HQ, Nanson GC. 2000. Hydraulic geometry and maximum flow efficiency as products of the principle of least action. Earth Surface Processes and Landforms 25: 1-16.

Huang HQ, Nanson GC. 2001. Alluvial channel-form adjustment and the variational principle of least action. Proceedings of the XXIX IAHR Congress, Beijing, Theme D; 410-415. 
Huang HQ, Nanson GC. 2002. A stability criterion inherent in laws governing alluvial channel flow. Earth Surface Processes and Landforms 27: 929-944.

Huang HQ, Nanson GC. 2004. 'Least action principle' and 'maximum flow efficiency'. In Encyclopaedia of Geomorphology, Goudie AS (ed.). Routledge: London; 616-617, 654-655.

Huang HQ, Nanson GC. 2007. Why some alluvial rivers develop an anabranching pattern. Water Resources Research 43: W07441. DOI: 10.1029/2006WR005223

Huang HQ, Nanson GC, Fagan SD. 2002. Hydraulic geometry of straight alluvial channels and the principle of least action. Journal of Hydraulic Research 40: 153-160.

Huang HQ, Nanson GC, Fagan SD. 2004b. Reply: Hydraulic geometry of straight alluvial channels and the principle of least action. Journal of Hydraulic Research 42: 220-222.

Huang HQ, Warner RF. 1995. The multivariate controls of hydraulic geometry; a causal investigation in terms of boundary shear distribution. Earth Surface Processes and Landforms 20: 115-130.

Huang Wan-Li. 1983. The extremity laws of hydro-thermodynamics. Applied Mathematics and Mechanics 4: 499-510.

Huang Wan-Li. 1988. The law of maximum rate of energy dissipation. Proceedings of International Symposium on Hydraulics for High Dams, Beijing; 159-165.

Ikeda S. 1981. Self-formed straight channels in sandy beds. Journal of the Hydraulics Division, ASCE 107: 389-406.

Ikeda S, Parker G, Kimura Y. 1988. Stable width and depth of straight gravel rivers with heterogeneous bed materials. Water Resources Research 24: 713-722.

Inglis CC. 1947. Meanders and Their Bearing on River Training. Maritime and Waterways Engineers Division, Institution of Civil Engineers: London.

Jansen JD, Nanson GC. 2004. Anabranching and maximum flow efficiency in Magela Creek, northern Australia. Water Resources Research 40: W04503. DOI: 10.1029/2003WR002408, 1-12

Jefferson MSW. 1902. Limiting width of meander belts. National Geography Magazine 373-384.

Jia Y. 1990. Minimum Froude number and the equilibrium of alluvial sand rivers. Earth Surface Processes and Landforms 15: 199-209.

Julien PY, Wargadalam J. 1995. Alluvial channel geometry: theory and applications. Journal of Hydraulic Engineering, ASCE 121: 312325.

Kirkby MJ. 1977. Maximum sediment transporting efficiency as a criterion for alluvial channels. In River Channel Changes, Gregory KJ (ed.). Wiley: New York; 450-467.

Knighton D. 1998. Fluvial Forms and Processes: a New Perspective. Arnold: London.

Kovacs A, Parker G. 1994. A new vectorial bedload formulation and its application to the time evolution of straight river channels. Journal of Fluid Mechanics 267: 153-184.

Kroemer H. 1994. Quantum Mechanics: for Engineering, Materials Science, and Applied Physics. Prentice-Hall: Englewood Cliffs, NJ.

Lacey G. 1929. Stable channels in alluvium. Proceedings of the Institution of Civil Engineers, London 229: 259-292.

Lacey G. 1933. Uniform flow in alluvial rivers and canals. Proceedings of the Institution of Civil Engineers, London 237: $421-453$.

Lacey G. 1946. A general theory of flow in alluvium. Proceedings of the Institution of Civil Engineers, London 27: 16-47.

Lacey G. 1958. Flow in alluvial channels with sandy mobile beds. Proceedings of the Institution of Civil Engineers, London 11: 145164.

Lane EW. 1955. The importance of fluvial geomorphology in hydraulic engineering. Proceedings of the American Society of Civil Engineers 81: 1-17.

Lamberti A. 1988. About extremal hypotheses and river regime. In River Regime, White WR (ed.). Wiley: New York; $121-134$.

Lanczos C. 1952. The Variational Principles of Mechanics. University of Toronto Press: Toronto.

Langbein WB. 1964. Geometry of river channels. Journal of the Hydraulics Division, ASCE 90: 301-312.

Langbein WB, Leopold LB. 1966. River Meanders - Theory of Minimum Variance, US Geological Survey Professional Paper 422H.

Leopold LB, Langbein WB. 1962. The Concept of Entropy in Landscape Evolution, US Geological Survey Professional Paper 500A.

Leopold LB, Maddock T Jr. 1953. The Hydraulic Geometry of Stream Channels and Some Physiographic Implications, US Geological Survey Professional Paper 252.

Mackin JH. 1948. Concept of the graded river. Bulletin of the Geological Society of America 59: 463-512.

Makaske B. 2001. Anastomosing rivers: a review of their classification, origin and sedimentary products. Earth-Science Review 53: 149196.

Meyer-Peter E, Müller R. 1948. Formulas for bed load transport. Paper presented at the Third Meeting of the International Association for Hydraulic Research (IAHR), Stockholm.

Millar RG. 2005. Theoretical regime equations for mobile gravel-bed rivers with stable banks. Geomorphology 64: $207-220$.

Millar RG, Quick MC. 1993. Effect of bank stability on geometry of gravel rivers. Journal of Hydraulic Engineering, ASCE 119: 13431363.

Millar RG, Quick MC. 1998. Stable with and depth of gravel-bed rivers with cohesive banks. Journal of Hydraulic Engineering, ASCE 124: $1005-1013$.

Mosselman E. 2000. Discussion: River width adjustment I: processes and mechanisms. Journal of Hydraulic Engineering, ASCE 126: 159160.

Mosselman E. 2004. Discussion: Hydraulic geometry of straight alluvial channels and the principle of least action. Journal of Hydraulic Research 42: 219-220.

Nanson GC, Huang HQ. 1999. Anabranching rivers: divided efficiency leading to fluvial diversity. In Varieties of Fluvial Form, Miller AJ, Gupta A (eds). Wiley: New York; 477-494. 
Nanson GC, Knighton AD. 1996. Anabranching rivers: their cause, character and classification. Earth Surface Processes and Landforms 21: 217-239.

Parker G. 1978a. Self-formed straight rivers with equilibrium banks and mobile beds, 1, the sand-silt river. Journal of Fluid Mechanics 89: $109-125$.

Parker G. 1978b. Self-formed straight rivers with equilibrium banks and mobile beds, 2, the gravel river. Journal of Fluid Mechanics 89: 127-146.

Parker G. 1979. Hydraulic geometry of active gravel rivers. Journal of the Hydraulics Division, ASCE 105: 1185-1201.

Phillips JD. 1991. Multiple modes of adjustment in unstable river channel cross-sections. Journal of Hydrology 123: 39-49.

Phillips JD. 1992. The end of equilibrium? Geomorphology 5: 195-201.

Pickup G. 1976. Adjustment of stream-channel shape to hydrologic regime. Journal of Hydrology 30: 365-373.

Pizzuto JE. 1990. Numerical simulation of gravel bed widening. Water Resources Research 26: 1971-1980.

Richards KS. 1982. Rivers: Form and Process in Alluvial Channels. Methuen: London.

Richards K. 1999. The magnitude frequency concept in fluvial geomorphology: a component of a degenerating research programme? Zeitschrift fur Geomorphologie Supplement 115: 1-18.

Russell B. 1997. The ABC of Relativity, 5th rev. edn. Routledge: London.

Schoklitsch A. 1937. Hydraulic structure, Schulits S (transl.). Proceedings of American Society of Mechanical Engineering $504-511$.

Schroeder M. 1991. Fractals, Chaos, Power Laws - Minutes from an Infinite Paradise. Freeman: New York.

Schumm SA. 1960. The Shape of Alluvial Channels in Relation to Sediment Type, US Geological Survey Professional Paper 352B; 17-30.

Schumm SA. 1977. The Fluvial System. Wiley: New York.

Schumm SA, Winkley BR. 1994. The Variability of Large Alluvial Rivers. ASCE Press: New York.

Simon A. 1992. Energy, time, and channel evolution in catastrophically disturbed fluvial systems. Geomorphology 5: $345-372$.

Simons DB, Albertson ML. 1960. Uniform water conveyance channels in alluvial materials. Journal of the Hydraulics Division, ASCE 86: $33-71$.

Smith DG, Smith ND. 1980. Sedimentation in anastomosed river systems: examples from alluvial valleys near Banff, Alberta. Journal of Sedimentary Petrology 50: 157-164.

Song CCS, Yang CT. 1980. Minimum stream power theory. Journal of the Hydraulics Division, ASCE 106: 1477-1487.

Song CCS, Yang CT. 1982. Minimum energy and energy dissipation rate. Journal of the Hydraulics Division, ASCE 108: 690-706.

Stauffer D. 2005. Teaching Reiser's extremal principle for hydrodynamics. American Journal of Physics 73: $282-283$.

Stauffer D, Stanley HE. 1989. From Newton to Mandelbrot: a Primer in Theoretical Physics. Springer: New York.

Tabata KK, Hickin EJ. 2003. Interchannel hydraulic geometry and hydraulic efficiency of the anastomosing Columbia River, southeastern British Columbia, Canada. Earth Surface Processes and Landforms 28: 837-852. DOI: 10.1002/esp.497

Thorn CE, Welford MR. 1994. The equilibrium concept in geomorphology. Annals of the Association of American Geographers 84: 666-696.

Tinkler KJ. 1997a. Critical flow in rockbed streams with estimated values for Manning's n. Geomorphology 20: 147-164.

Tinkler KJ. 1997b. Indirect velocity measurement from standing waves in rocked rivers. Journal of Hydraulic Engineering, ASCE 123: 918921.

Tooth S, Nanson GC. 1999. Anabranching rivers on the Northern Plains of arid central Australia. Geomorphology 29: 211-233.

Tooth S, Nanson GC. 2000. The role of vegetation in the formation of anabranching channels in an ephemeral river, Northern Plains, arid central Australia. Hydrological Processes 14: 3099-3117.

Vigilar GG, Diplas P. 1997. Stable channels with mobile bed: formulation and numerical solution. Journal of Hydraulic Engineering, ASCE 123: $189-199$.

Vigilar GG, Diplas P. 1998. Stable channels with mobile bed: model verification and graphical solution. Journal of Hydraulic Engineering, ASCE 124: 1097-1108.

Wang SQ, White WR, Bettess R. 1986. A rational approach to river regime. Proceedings of the Third International Conference on River Sedimentation. Jackson, Mississipp; 167-176.

Wang SQ, Zhang R. 1989. Cause of formation of channel patterns and pattern predictions. Proceedings of XXIII IAHR Congress, Ottawa, Ontario; B131-B136.

Wende R, Nanson GC. 1998. Anabranching rivers: ridge-form alluvial channels in tropical northern Australia. Geomorphology 22: $205-224$.

White WR, Bettess R, Paris E. 1982. Analytical approach to river regime. Journal of the Hydraulics Division, ASCE 108: 1179-1193.

Wilczek F. 2004. Whence the force of $F=m a$ ? I. Culture shock. Physics Today 57: 11-12.

Wolman MG, Miller JP. 1960. Magnitude and frequency of forces in geomorphic processes. Journal of Geology 68: 54-74.

Yalin MS, Silva AMF. 1999. Regime channels in cohesionless alluvium. Journal of Hydraulic Research 37: 725-742.

Yalin MS, Silva AMF. 2000. Computation of regime channel characteristics on thermodynamics basis. Journal of Hydraulic Research 38: 57-64.

Yang CT. 1971. On river meanders. Journal of Hydrology 13: 231-253.

Yang CT. 1972. Unit stream power and sediment transport. Journal of the Hydraulics Division, ASCE 98: 1805-1826.

Yang CT. 1976. Minimum unit stream power and fluvial hydraulics. Journal of the Hydraulics Division, ASCE 102: 919-934.

Yang CT. 1987. Energy dissipation rate approach in river mechanics. In Sediment Transport in Gravel-Bed Rivers, Thorne CR, Bathurst JC, Hey RD (eds). Wiley: New York; 735-766.

Yang CT, Song CCS. 1979. Theory of minimum rate of energy dissipation. Journal of the Hydraulics Division, ASCE 105: 769-784.

Yang CT, Song CCS, Woldenberg MJ. 1981. Hydraulic geometry and minimum rate of energy dissipation. Water Resources Research 17: $1014-1018$.

Zipf GK. 1949. Human Behavior and the Principle of Least Effort. Addison-Wesley: Cambridge, MA. 